\title{
EL LABERINTO LITERARIO \\ DE LAS POETAS MAYAS YUCATECAS CONTEMPORÁNEAS
}

\author{
Óscar Ortega Arango \\ Universidad Autónoma de Yucatán
}

Resumen: Este artículo tiene como objetivo presentar una aproximación a la poesía lírica maya yucateca contemporánea escrita por mujeres a partir de un enfoque que discute las aportaciones/continuidades literarias de estas realizaciones artísticas al interior de la propia tradición maya y su diferencia con la tradición occidental. Para realizar dicho objetivo, se inicia con una reflexión sobre los principales elementos de análisis a las literaturas indígenas que, en parte, han limitado dentro del universo de la crítica literaria la construcción de un cuerpo de estudios que permitan observar las importantes transformaciones que a nivel de géneros literarios se vienen realizando en dichos movimientos creativos. En esta dirección, sobresale la presencia de autoras que se encuentran aportando propuestas líricas que actualizan la tradición cultural maya, pero, además, discuten y reorientan algunos elementos de la lírica occidental.

Palabras clave: lírica, maya, contemporánea, género, mujeres.

ABSTRACT: This article approaches contemporary lyrical poetry written by Yucatan Maya women by discussing the literary contributions/continuities of the artistic manifestations inside the Mayan tradition and their differences with Western tradition. To do so the article begins with a reflection on the elements of study of indigenous literature that, in part, have been limited to the construction of literary analysis of a body of studies that allows one to observe the important transformations that, on a level of literary genres, come into being in such creative movements. The presence of female authors such as those that can be found supporting lyrical proposals that renew the Maya cultural tradition are notable but also discuss and reorient some elements of Western lyric.

KEYWoRDs: lyric, Maya, contemporary, gender, women.

RECEPCIÓN: 6 de diciembre de 2012.

ACEPTACIÓN: 11 de marzo de 2013. 



\title{
EL LABERINTO LITERARIO DE LAS POETAS MAYAS YUCATECAS CONTEMPORÁNEAS
}

\author{
Óscar Ortega Arango \\ Universidad Autónoma de Yucatán
}

La literatura contemporánea del continente americano se ha revitalizado con la aparición de una serie de escritores de origen indígena que, publicando sus textos en las lenguas originarias o en formato bilingüe, han incursionado con fuerza en el espectro literario y, en particular, en el género poético. Es así que a lo largo y ancho de América se han publicado, en las últimas décadas, obras en lenguas amerindias como el náhuatl, el zapoteco, el aimara y el maya, entre otras.

En la Península de Yucatán el fenómeno de creación poética recibió un impulso con el fomento del estudio de la lengua maya que fue promovido por el Instituto Nacional Indigenista entre 1959 y 1972. Es decir, el esfuerzo por alfabetizar a la población en lengua maya fortaleció las expresiones de creación literaria que ya se venían presentando, como la revista Yikal Maya Than (1939-1955). ${ }^{1}$ La década de los setenta es rica en esfuerzos de los profesores, para entonces ya alfabetizados en lengua maya, que se dedicaron a difundir y fomentar el uso de su lengua, utilizando, entre otras estrategias, la escritura creativa (Leirana, 2011: 12-13). En los años ochenta un importante grupo de escritores maya hablantes se aglutinó en torno de la Unidad Regional de Culturas Populares, que auspició diversos talleres de lengua y literatura maya y apoyó proyectos de periodismo en los que podían dar a conocer sus creaciones. Asimismo, los profesores y escritores en lengua maya fueron ganando espacios en las radiodifusoras comunitarias con programas monolingüies o bilingües, en maya y español (Leirana, 2011: 19-23). Las frecuencias de radio permitieron aumentar los receptores de las creaciones literarias, hablar sobre temas relevantes para las comunidades y, sobre todo, fomentar el uso de la lengua maya. Poco a poco, proliferaron los grupos o asociaciones de escritores bilingüies interesados en tener capacitación en materia literaria y fomentar la publicación de sus trabajos. La labor de estos grupos de escritores ha sido tan relevante que en el Catálogo de textos mayas publicados entre 1990 y 2009, realizado por Silvia Cristina Leirana Alcocer, se encuentran registrados más

\footnotetext{
${ }^{1}$ Yikal Maya Than fue una revista de literatura maya dedicada a la difusión de tradiciones, leyendas, trabajos históricos, lecciones en lengua maya, literatura y semblanzas de Yucatán. Fue publicada bajo la dirección del profesor Paulino Novelo, miembro de U Mulay Ah Maya Than, academia de la lengua maya fundada por el antropólogo Alfredo Barrera Vásquez (Enciclopedia Yucatán en el tiempo, 1999, tomo VI: 163).
} 
de 100 escritores con obras publicadas en maya o en maya y español. Entre este abundante corpus de autores resaltan por su calidad en la labor poética escritores como Santiago Domínguez Aké, Briceida Cuevas Cob, Flor Marlene Herrera Manrique, Feliciano Sánchez Chan, Silvia Canché Cob, Gertrúdiz Puch Yah, Margarita Kú Xool y Waldemar Noh Tzec, entre otros.

Es innegable que la escritura de los poetas mayas contemporáneos se encuentra vinculada a los proyectos culturales que han desarrollado instituciones gubernamentales, organismos de la sociedad civil y los mismos colectivos de escritores, para promover la lengua y la literatura maya. Seguramente por ello un número importante de estos escritores intentan, en primera instancia, revitalizar al interior de su comunidad valores que reconocen como "propios" y, en particular, el uso de la lengua maya. Miguel May May, uno de los escritores mayas contemporáneos más prolíferos, declara esta intención en el epígrafe de un libro de Francesc Ligorred:

Un aumento en el número de escritores y de producciones literarias en maya suministrará la cantidad suficiente de materiales para apoyar las labores de alfabetización [...] y con esto se logrará crear conciencia de la necesidad de preservar y desarrollar nuestra lengua materna para afirmar nuestra identidad y engrandecer nuestra propia cultura. (Ligorred, 1997: 7).

Por ello, en muchos de los trabajos surgidos de los talleres literarios que se han impartido para escritores mayas se percibe un intento de reflexión sobre la identidad cultural maya, la recopilación de la tradición oral y un vínculo fuerte con la promoción cultural y la docencia (Ortega, 2010: 21). Desde esta perspectiva, la literatura maya contemporánea, más que buscar una directa relación con la estética interna (propia de otros textos literarios), tiene el interés, al menos explícito, de hacer llegar a la comunidad textos que recuperen la memoria tradicional y permitan el uso, la lectura y el aprendizaje de la lengua maya.

Reconociendo la importancia del objetivo antes planteado, pero entendiendo que la literatura es un arte, resulta pertinente cuestionar icuál es el aporte distintivo que realizan los escritores mayas en la construcción de obras poéticas que intentan participar de la conservación/pervivencia de su mundo cultural? Para resolver lo anterior es importante reconocer que la labor poética de los escritores mayas se encuentra influenciada por la tradición literaria occidental, no sólo en el nivel de los contenidos, sino en el proceso mismo de selección de determinados géneros y subgéneros literarios.

En este sentido, es importante aceptar que, pese a los grandes esfuerzos realizados por antropólogos, profesores y escritores, todavía se carece de una reflexión profunda sobre lo que se conceptualiza como poesía en el universo literario maya-yucateco contemporáneo y, más aún, se adolece de un análisis profundo sobre las implicaciones de los subgéneros en los que dichos autores escriben. Lo anterior es de vital importancia pues, como comenta Edmund Cros: 
[...] toda colectividad inscribe en su discurso los indicios de su inserción espacial, social e histórica, y genera, por consiguiente, microsemióticas específicas. Nos hemos esforzado por describir los niveles en que dichos indicios eran localizables. Resultó que las huellas más evidentes se encontraban en los ejes paradigmáticos, las expresiones hechas, los sintagmas fijos, las lexías. La forma de lexicalizarse las lexías, a nuestro juicio, transcribe de modo mucho más directamente perceptible el sistema de valores sociales, y las alteraciones que los modifican, los modos de vida y de inserción socioeconómica de los medios que los producen, así como las evoluciones de las estructuras mentales. (Cros, 1986: 27-28).

La forma en la que se manifiestan estas microsemióticas en los textos literarios resulta relevante porque toda práctica discursiva "[...] implica siempre una sociabilidad del acto de habla y una relación profunda con la historia” (Cros, 1986: 59). Por tanto, la presencia de determinadas formas de expresión (o su ausencia) y la elección de ciertos géneros literarios (por ejemplo la poesía) son indicadores de primer orden de las formas en que diversos grupos sociales transcriben sus realidades y crean sus configuraciones sociales. Es decir, lo que debemos analizar son "[...] las condiciones históricas de posibilidad de emergencia del objeto del discurso", pues "los campos perceptivos se reorganizan en función de las mutaciones que afectan a las instituciones y a las prácticas sociales" (Cros, 1986: 60).

En esta dirección, se debe considerar que la publicidad que reciben, hoy por hoy, las obras literarias publicadas en maya-español no centra su atención en la calidad, género, subgénero o propuesta de las obras, sino en el origen étnico de los autores. Esto se puede observar en algunas ferias literarias, presentaciones de libros, foros literarios y hasta páginas web. Lo anterior puede ser síntoma de una inserción particular dentro de una dinámica interna del sistema ideológico/ cultural que programa dicha manifestación, porque la ideología, como afirma Cros, interviene en todo el circuito de comunicación cultural:

Al modelar la experiencia y todos los fenómenos —individuales o colectivos- de conciencia, la ideología interviene, efectivamente — como hemos visto-, en todos los estadios de la producción de sentido y, de manera general, en todos los circuitos de comunicación cultural. De ahí el interés que tiene actualizar la complejidad de estas redes de ideosemas en los que se materializa el texto. (Cros, 1986: 91-92).

Esta forma de mercadeo (efectiva en término de ventas, sobre todo con el público extranjero) pone de manifiesto, en el circuito literario, la existencia de grupos de creadores en las lenguas originarias de América. Sin embargo, resulta limitante, ya que el hecho de que un texto sea escrito por un autor maya (es decir, que el autor "real" asuma una identidad étnica y cultural determinada) no significa que dicha producción estética proponga una reorganización o una reflexión sobre las configuraciones culturales y simbólicas propias de su etnia; sino que, más bien, ejerce un tipo de presión particular dentro del circuito li- 
terario. Lo anterior se hace del todo evidente cuando las obras de los autores mayas se consiguen más fácilmente en los expendios de los sitios arqueológicos de la península yucateca que en las grandes librerías de las principales ciudades. Esta situación conlleva el peligro de quedar atrapados en una dinámica (entre lector, escritor y editor) que relaciona, de manera directa, temáticas específicas con las obras de los autores mayas, lo cual significa limitar su capacidad creativa. Además, esta visión olvida o deja de lado los elementos relacionados con el valor estético de los textos literarios. Es decir, el receptor-lector busca un tipo de significados, una vez que, ubicado en un contexto específico, recibe una "orden" interna del sistema social y cultural al cual pertenece que le informa que en esos discursos literarios se encontrarán elementos que presentan valores estéticos fundamentales reconocidos por la comunidad. Como se ve, el problema del significado no se asocia única y exclusivamente con el objeto artístico en sí, sino con los ordenamientos sociales que me indican lo que "se debe" observar en dichas manifestaciones y, aun más, lo que se considera especialmente valioso en ellas.

Para ahondar en este punto, recordemos los aportes que realizó Mijaíl Bajtín en su texto El problema del contenido, del material y de la forma en los estudios literarios. En él, el teórico ruso determina a los contenidos (es decir, las temáticas) sólo como una parte de lo que constituye la obra estética. Estos contenidos no son puros (en el sentido de una observación verosímil plasmada en el discurso), sino que, al seleccionarlos, se les imprime una valoración de carácter ético. Sin embargo, aunque el contenido tiene un valor ético cognitivo, es tan sólo un elemento material de lo que va a constituir el verdadero valor estético de una obra: la forma. Para Bajtín la forma se construye por medio del proceso de transformación del todo verbal linguí́stico (material y contenido) en un todo arquitectónico acabado estéticamente. Es decir, la forma arquitectónica de un texto literario: "[...] es forma del contenido realizada en el material y sujeta a él" (Bajtín, 1997: 45).

Es decir, la posición del sujeto emisor del discurso se relaciona, no sólo con una identidad étnica del autor, sino también con múltiples identidades culturales que dejan huellas dentro del texto. Estas presencias quedan plasmadas en los diferentes elementos gramaticales y en diversas temáticas que el autor escogió para articular de forma particular su texto. Así, todo discurso estético significa mucho más que una temática escogida o la identidad étnica del autor real, para emerger como un interdiscurso con diversos caminos.

Por ello, un estudio a las creaciones literarias que profundice en el análisis de las transformaciones del esquema linguístico establecido, en busca de una forma estética donde se proponga (de forma implícita, por supuesto) una modificación (o perpetuación) de los valores que subyacen dentro de una determinada organización social, es de suma importancia para avanzar en el conocimiento de la literatura maya contemporánea. Y es allí (en ese momento) donde se puede considerar si una obra literaria determinada manifiesta una crítica o una propuesta a determinadas construcciones culturales. Además, sería inocente considerar que 
el hecho de que escoger una temática particular no lleva implícito el tratamiento de otros factores sociales y literarios donde, a pesar de mostrar reivindicaciones en un orbe determinado, se puede ser profundamente reaccionario en otros.

Los planteamientos teóricos antes enunciados dirigen la cuestión a la determinación histórica de los elementos presentes en las obras a partir de la historia literaria que los escritores mayas actualizan en su presente. Por ello, es necesario poner atención en la secuencia significativa de la obra literaria, la cual emana de la historicidad literaria no sólo de un grupo cultural, sino de todos los interdiscursos a los cuales el emisor (como usuario de los diversos contextos culturales) puede acceder. Por ello, en la revisión del "presente" de emisión de una obra artística se debe incluir una aproximación sincrónica del momento de generación de dicho discurso. Desde esta perspectiva, y en directa relación con los poetas mayas contemporáneos, vale la pena reflexionar sobre el género literario que escogieron para realizar su obra y las consecuencias o direcciones que se asumieron desde tal perspectiva.

Lo anterior es relevante ya que, como afirma Michal Glowinski, "el sistema de los géneros determina de una manera específica las prácticas literarias, tanto en el plano de la emisión como en el de la recepción" (2002: 98). Esta relación resulta de vital importancia pues, en los estudios literarios, "[...] hemos dejado de lado todo lo que tiene que ver con su evolución histórica, con su pertenencia a una civilización o a una cultura nacional concreta" (Glowinski, 2002: 100). Así, la tarea de encontrar el mapa de reflexión sobre las obras literarias particulares de los diversos poetas mayas contemporáneos tiene que tomar en consideración una relación con el género literario que se escogió, pues éste no resulta estático y acabado, sino, al contrario, “[...] su naturaleza y su extensión cambian en función de múltiples factores, puesto que aquello que es posible en una determinada situación literaria deja de serlo en otra" (Glowinski, 2002: 101). En este contexto, "un género no funciona plenamente hasta que es identificado por el público literario, convirtiéndose así en un coeficiente de lectura" (Glowinski, 2002: 105), lo cual, a su vez, "[...] determina un cierto marco de interpretación" (Glowinski, 2002: 109).

Resumiendo lo anterior se puede afirmar que la labor de creación poética, vista desde el perfil de un género literario, está influenciada por los talleres literarios que se desarrollaron en la Península de Yucatán en los últimos años ${ }^{2}$ y mediante los cuales se realizó un distanciamiento y una incorporación de

\footnotetext{
${ }^{2}$ Particular mención merecen, en este sentido, talleres como el de la Unión Regional de Culturas Populares de Yucatán (Mérida, Yucatán), el taller de Calkiní (Campeche) y el taller de Yaajal K’in, el cual, en cercana relación con la organización Mayaón A. C., se lleva a cabo en Valladolid (Yucatán). En el taller de Calkiní, debido a la formación e inclinaciones de su director, se trabaja con especial énfasis poesía, y sus miembros se han acercado al estudio de las vanguardias españolas. En el taller de la Unidad Regional de Culturas Populares de Yucatán, fundado por el recién fallecido escritor Carlos Montemayor, se percibe una inclinación más hacia la narrativa y el rescate de la tradición oral (Ortega, 2010: 61-68).
} 
diversos elementos de la tradición occidental. Para observar el funcionamiento de los anteriores planteamientos en obras concretas, se eligió revisar el aporte que hacen tres poetas mayas contemporáneas: Briceida Cuevas Cob, Silvia Canché Cob y Margarita Kú Xool. La selección obedece a que las tres incursionan en el género poético, desde el subgénero lírico, han compartido espacios de publicación y han logrado tener presencia considerable por su constancia en la escritura y su calidad poética. Sin embargo, antes de abordar directamente su obra, es importante precisar algunos elementos relacionados con el género poético.

\section{La poesía lírica como deseo del retorno}

La poesía lírica era, en su origen, aquella que se acompañaba de un instrumento musical para su interpretación. En el caso de la cultura maya no se debe olvidar que el documento clave de la poesía en lengua maya son los Cantares de Dzitbalché; en este texto se establece que se trata de "El libro de las Danzas / de los hombres antiguos / que era costumbre hacer / aquí en los pueblos (de Yucatán) cuando / aun no / llegaban los blancos" (Barrera, 1980: 37), los cuales se acompañaban con música y danza y, en palabras de Yershova, " [...] se distinguen por su profundo contenido lírico” (1983: 40). Con ello, se muestra que la poesía lírica tiene una historicidad amplia como subgénero poético preeminente dentro de la tradición maya.

Ahora lo importante de la selección poética del subgénero lírico radica en que en ella predomina el sentimiento subjetivo del poeta, es decir, su deseo de autoafirmación. Lo anterior permite a Helena Beristáin afirmar sobre el "yo" enunciador lírico:

Así, pues, el sujeto enunciador del discurso es un conducto que comunica lo intratextual con lo extratextual, cumpliendo un papel semejante al de los embragues - shifters - (capaces de hacer referencia al proceso de la enunciación con sus protagonistas: emisor y receptor, y al proceso de lo enunciado con sus protagonistas: los personajes), ya que a su través pasan, desde el contexto, las determinaciones biológicas, psíquicas, sociales, artísticas y, en general, histórico-culturales, que se manifiestan como texto. (Beristáin, 1989: 48-49).

Por ello, "[...] el poema lírico es el tipo de discurso literario en el cual el "yo" enunciador no desempeña un papel ficcional (a diferencia del narrador de la novela, el cuento, la epopeya, etcétera, así como del autor que construye un drama y del actor que lo representa), pues, aunque cumple un papel literario, éste no es un papel ficticio: se desarrolla fuera de la ficción" (Beristáin, 1989: 49). Por ello, como afirma Kayser respecto a la lírica, la actitud típica del sujeto de la enunciación es la de "[...] manifestar su propia intimidad, sus emociones, sensaciones, experiencias y estados de ánimo" (1961: 321). 
Lo importante de tales cuestiones es que en el subgénero lírico

[...] el "yo" enunciador del poema lírico permanece fundido con el "yo" del autor, a diferencia de lo que ocurre en los otros géneros literarios, pues el poeta comunica desde una experiencia auténtica por el hecho de que no desempeña un "rol" ficcional pues no se inviste, como el "yo" dramático, del carácter de los personajes, ni se sitúa frente al público como en el teatro, ni se ubica frente al "tú" del oyente como en el poema épico, sino frente a sí mismo; pero sobre todo porque el "yo" del poeta lírico difícilmente podría concebirse separado del yo social que cumple otros papeles. (Beristáin, 1989: 50).

En otras palabras, reafirma Beristáin, "[...] el poeta no abdica de su naturaleza creadora ni cuando duerme y sueña y, mientras desempeña su papel literario, en él se da una perfecta identificación entre el "yo" constructor del discurso lírico y el "yo" social del autor, que involucra todos sus demás 'roles' virtuales" (Beristáin, 1989: 51).

La diferencia, frente a otros subgéneros poéticos (del enunciador lírico al enunciador epopéyico, por ejemplo), permite a Roman Jakobson afirmar que "reduciendo el problema a una simple formulación gramatical, puede decirse que la primera persona es a la vez el punto de partida y el tema conductor de la persona lírica, mientras que este 'rol' es cumplido en la epopeya por la tercera persona de una forma del pretérito” (1973: 53). Así, en la poesía lírica

se trata de un "lenguaje interior", de una "autocomunicación”, que es un modo de comunicación peculiar de la poesía lírica. El mensaje no se transmite según la fórmula yo-tú, sino según la fórmula yo-yo (aunque exista la intención de compartir el poema, repito, y el poeta prevea la existencia de un público), donde el emisor y el destinatario son el mismo en una primera instancia inmersa dentro del marco de una comunicación (quizá considerada simultánea, pero en segunda instancia) del tipo yo-tú, en la que el emisor y el destinatario son diferentes. (Beristáin, 1989: 54).

Cesare Segre (1985) esquematiza lo anterior de la siguiente manera:

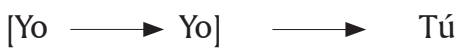

En este contexto, el propio subgénero lírico ha tenido etapas. Por ejemplo, en la lírica antigua occidental las imágenes poéticas son muy ricas debido a su complejo empleo de símbolos, que aparecen ligados preferentemente a la naturaleza. Así, la lírica occidental servía como acompañante de discursos religiosos, particularmente de La Biblia, o se incorporó a otros géneros como el teatro, la novelística, la poesía o la historia. Incluso, es un hecho comprobado que la cultura oral, y dentro de ella la lírica tradicional, desempeña una función social más importante cuanto más reconocimiento de su tradición tenga y menos condicionada esté la sociedad por la cultura de transmisión escrita y, por supuesto, por la moderna cultura audiovisual de masas.

Por todo ello, el subgénero poético lírico resulta ser un tipo específico de poesía que concilia diversos elementos en su propia realización. Uno de ellos 
(tal vez el más importante) resulta el convertirse en una forma de expresión ubicada desde el "yo" subalternizado frente al discurso homogéneo de una cultura impuesta a partir de un deseo de autoafirmación. En este sentido, y aunque son pocos e indirectos los ejemplos y se presentan a través de historiadores romanos o latino-medievales, hay que mencionar a la lírica tradicional hispánica que, finalmente, rematará en las jarchas mozárabes de los siglos xı y xil. Estas pequeñas cancioncillas en romance mozárabe vulgar se insertaban como desenlace de muwashahas o moaxajas, complejos y elaborados poemas en árabe clásico o en hebreo. Se cree que los autores árabes y judíos, que conocían la lengua y la tradición popular, las incluían atraídos por su hermosa y elemental belleza poética. Muy poco después empiezan a documentarse los refrains franceses y las cantigas de amigo galaico-portuguesas, que tienen en común con las jarchas, aparte de ciertas imágenes y rasgos estilísticos, el ser una lírica que presenta una voz identificada como femenina y reflejar sus puntos de vista sobre el amor y la vida. Mientras la épica, sus héroes, sus difusores, transmisores y su función se han asociado preferentemente al mundo masculino, la lírica, desde sus orígenes hasta hoy, ha estado estrecha, aunque no exclusivamente, ligada a la mujer como creadora y transmisora. Esto es muy importante, pues es un fenómeno que se repite en la literatura maya contemporánea con autoras como las ya mencionadas.

\section{Briceida Cuevas Cob: posibilidades de encuentro}

Nacida en Tepakán, Calkiní (Campeche), ha colaborado en diversas publicaciones (regionales y nacionales), en periódicos y revistas. Una de sus obras poéticas con mayor reconocimiento es "U yok'ol avat pek' t'i u kuxtal pek" ("El quejido del perro en su existencia") (Cuevas, 1996); ${ }^{3}$ algunos de sus fragmentos fueron editados en 1996 por la revista Navegaciones Zur. El poema está dividido en dos partes y publicado en maya y en español. La perra configurada en dicho texto no tiene ninguna característica que la haga particularmente hermosa. Es como una de tantas perras que recorren los pueblos y ciudades de Yucatán. Es una perra máalix, sin raza específica, de la que se desconoce la cruza que le dio origen; así se puede ver en los primeros tres versos:

Ella es una perra común.

Nunca deseó el rizo de nubes en su piel,

Ni la cola de la ardilla.

Vale la pena comentar que desde el propio título se inicia una transformación frente al universo lírico occidental. La conjunción del elemento "perro" con la

\footnotetext{
${ }^{3}$ Todas las referencias fueron tomadas de esta edición.
} 
trascendencia ("existencia”) lastimera (“quejido") informa sobre el proceso de humanización que sufre este elemento no humano frente al cual la voz poética, simplemente, presenta los sentimientos percibidos. Cabe recordar que el perro, dentro de la cultura maya, remite a una estrecha relación con la vida y la muerte. A tal respecto, Robert J. Sharer, en La civilización maya apunta la importancia de este animal:

Aunque los antiguos mayas sí domesticaron a unos cuantos animales, éstos no eran fuente básica de su alimentación. Uno de ellos era el perro, descendiente de razas que acompañaron a los primero pueblos al entrar al nuevo mundo [...] y que era guardián del hogar y compañero de caza, como lo es hoy. (Sharer, 1998: 425).

La presencia cotidiana de los perros, entablada en diferentes situaciones sociales, genera una multiplicidad de papeles. Por citar sólo un caso, el perro aparece relacionado con la labor de los comerciantes. Así lo informa J. Eric. S. Thompson en Historia y religión de los mayas en relación con el Vaso de Ratinlixul (Gordon y Mason, 1925-43, parte 3, láms. 1 y 2), que es muestra de un viaje de comerciantes de cacao en donde el perro aparece con una función muy clara:

Es la única escena de la vida maya que yo conozca en cerámica donde se ve a un perro. Además, se le ve muy bien. Landa observa que en el mes Muan los dueños de plantaciones de cacao hacían una fiesta a Ek Chuah, Chac y Hobnil y sacrificaban un perro con manchas de color de cacao. Ek Chuah era el dios principal de los comerciantes yucatecos, quienes naturalmente tenían mucho que ver con el cacao. Por eso es razonable suponer que esos perros con marcas especiales estaban íntimamente relacionados con los comerciantes y sus rituales especiales. El perro de la escena de Ratinlixul tiene una mancha negra marcada en el lomo, y bien podría ser el perro relacionado con el ritual del cacao y por lo tanto de los comerciantes. (Thompson, 1975: 175-176).

Además de esta convivencia y la utilización del perro para el sacrificio, los mayas representan diversas deidades con la figura del perro:

Un informe algo posterior de 1583 menciona brevemente 1160 cizines (Cizín era el dios maya de la muerte y los españoles usaban su nombre para referirse a los diablos, o sea, los dioses paganos ). Los había tan grandes como un niño de tres a cinco años. Algunos llevaban en la cabeza figuras de animal, mitras o tiaras, otros eran representaciones de leones, jaguares y perros (Scholes y Adams, 1938; Scholes, Roys y Adams, 1945: 178). (Thompson, 1975: 236).

La importancia de este animal en la cultura maya llevó a que, en múltiples ocasiones, fuera enterrado con sus amos o, incluso, que su figura se tallara en sílex para ser colocada en las tumbas. Además, las continuas relaciones del hombre con los perros llevan a estos a convertirse en seres de la naturaleza que invitan a la reflexión. Así, en la segunda creación del Popol Vuh, los hombres hechos 
del árbol pito (tzité) son interrogados por los perros: "Los perros preguntaban a los hombres de palo por qué no los alimentaban y en cambio siempre tenían un garrote a mano para pegarles" (Thompson, 1975: 401).

La perra del poema de Briceida no es considerada una deidad, ni mucho menos apreciada por los hombres; no comprende su lugar en este mundo, no entiende ni su nombre:

No comprende su nombre

A veces se lo escriben en la cabeza con un leño

$A$ veces en la pata con una piedra,

$A$ veces en el vientre con una patada,

A veces con el desprecio en el rostro de las gentes

Cabe recordar que el perro se presenta como un elemento cultural importante que, al estar relacionado con la vida cotidiana y constituir un elemento representativo de la divinidad de la muerte (Cizín), surge, también, como un ser que interroga al hombre sobre su proceder, por eso en ocasiones causa temor o desprecio. Bajo este contexto se debe observar su funcionamiento en el poema "El quejido del perro en su existencia". En el fragmento II de la estructura de esta poesía, la voz poética se distancia para mostrar una transformación del espacio y de la mirada del hablante lírico:
Alguien se calzó las alpargatas de la maldad
Y dejó su huella en la iglesia
¿de qué sirve una multitud
si en cada gente silba la soledad?

Ese alguien, dice la voz poética, adquiere su caracterización física y simbólica por un elemento externo al "yo" interior (“alpargatas") que lo reconstruye en dirección de "la maldad", para incorporarlo a una convivencia social religiosa ("iglesia"). Ahora, este ser transformado (en sentido negativo) no se "reviste" con elementos extraños, ajenos, sino que se identifica con el mismo grupo: calza alpargatas y con ellas deja su huella en la iglesia. De tal forma, la voz poética reconoce que la presencia negativa de alguien ha imantado la totalidad de un ser social ("iglesia") que, implícitamente, se reconoce como positiva.

Hasta aquí, dos comentarios. En primer lugar recordemos que el proceso de evangelización en Yucatán tuvo como particular el hecho de que la asimilación por parte de los indígenas mayas de la religión católica monoteísta fue relativamente "sencilla", ya que los indígenas tomaron este nuevo dios y lo incorporaron en sus ritos como uno más de los múltiples existentes. Es decir, el espacio de la iglesia sólo corresponde a una parte del espacio ritual que los indígenas podían utilizar. Esto lleva a que la presencia del elemento negativo en la iglesia no cierra el contacto con la divinidad, sino que, más bien, lo desplaza. Unido a ello, y en segundo lugar, la voz poética señala la soledad (sentido de separación 
de los diversos "yo"), lo cual, en medio del rito religioso y con la iglesia llena, parecería contradictorio:

¿De qué sirve una multitud

si en cada gente silba la soledad?

La hipocrecía se santigua

Se ha enmarañado el pecho y el rostro en su santiguar.

De tal forma, la poeta encuentra un conflicto entre el mundo social y el mundo individual, que se genera en un rompimiento dado en un tiempo pasado pero que se evidencia en el presente: es la tensión entre "calzó" (pasado) y "sirve" (presente). Es decir, el individuo modificado por la "maldad" ha adquirido los rasgos sociales religiosos de la iglesia desplazando, en el presente, al "yo" poético hacia la soledad. Esta transformación hace que en "la gente" se produzca un encubrimiento: ya no son seres que se "santiguan" para la comunión con Dios, sino que, metamorfoseados por la hipocresía, adquieren los mismos gestos: lo anterior no es un rasgo, es la identidad profunda. De tal forma, la voz poética, distanciada de la vivencia social de un mundo religioso que se encuentra poseído por la impostura de la voz ("hipocresía"), logra avizorar diferentes elementos que han transformado el estado ideal pasado de la convivencia religiosa por uno nuevo donde "el rencor reza". En él, las "gentes" destruyen su voz pues "mastica[n] sus labios"; la mentira se postra para darse golpes de pecho, la vanidad tiene en las manos velas y en su brazos "un gran ramillete de flores". Frente a este mundo totalmente poseído por elementos negativos, la voz poética se siente solitaria, y se pregunta:

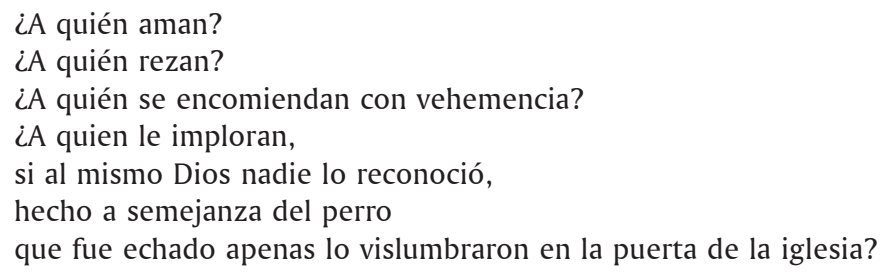

Esta tensión se profundiza cuando la voz poética afirma que Dios no está dentro de este espacio, pues "nadie lo reconoció". De tal forma, Dios (dentro de la estructura del poema) se presenta como una figura positiva que no fue entendida y, por tanto, ha sido separada de la vida comunitaria provocando que, el espacio dedicado a él, haya sido poseído por otro. Hasta aquí se tiene un poema que podría ser considerado como perteneciente a una tradición que discute la dicotomía Dios-iglesia como elementos no correspondientes. Así, se podría articular como un poema fruto del mundo ilustrado que, en busca de una moral laica (Lipovetsky, 1996), refrenda la imagen de Dios como guía y benefactor supremo, pero revalorando la institución de la Iglesia. También podría ser considerado 
como parte de la tradición occidental cuando el poeta (desde el romanticismo) se considera diferenciado del mundo social, pues este último ha perdido los valores verdaderos (Lukacs, 1985) para caer en un mundo de tinieblas; colocándose, a su vez, en un lugar que lo separa y lo enaltece ante el mundo caído.

Lo anteriormente señalado sería suficiente para considerar la obra como valiosa y reconocer en esta poeta maya a una escritora que no sólo contribuye a enaltecer un pasado, sino que, además, discute seria y profundamente con la vida religiosa de su comunidad. Pero, además de lo anterior, logra introducir un giro que resulta del todo novedoso en las literaturas de corte occidental. Este Dios, como ya se dijo, no fue reconocido, ni se le permitió el ingreso a la iglesia. Además, la voz poética dice que fue "hecho a semejanza del perro / que fue echado apenas lo vislumbraron en la puerta de la iglesia". Aquí, los semas "Dios" y "perro" comparten un elemento en común: no se les permitió el ingreso al espacio religioso cerrado y controlado por un grupo social. Esto permite visualizar uno de los elementos más significativos en la poesía de Briceida. En su obra se establece la comunión entre el mundo supraterreno (Dios) y el mundo terreno (perro), los cuales, fusionados entre sí por el elemento trascendencia, comparten su expulsión del mundo religioso social actual.

Por tanto, en el espacio exterior habitan los elementos escindidos pero que resurgen como los poseedores de los rasgos positivos. No se debe olvidar que para el proceso de evangelización de los mayas una de las mayores dificultades fue la de atraer a los indígenas al espacio de la iglesia (como templo cerrado) y hacer que ésta se convirtiera en su lugar de adoración. La respuesta, como se sabe, fue la apropiación del espacio no sólo para este Dios sino para otros dioses a quienes, en directa relación con su pasado, les rendían culto desde tiempos inmemoriales.

La voz poética, por tanto, ha dejado en tensión un mundo que, separado de las vivencias religiosas falsas, afirma que los valores verdaderos están fuera de la iglesia donde Dios existe en comunión con un mundo natural que ha sufrido las mismas vejaciones que él. Pero además, con la fusión de los semas "Dios" y "perro", se ha realizado la unión entre el mundo metafísico y el mundo físico natural: ambos comparten un quejido por su expulsión.

Sin embargo, ninguno está muerto, los dos conviven fuera de allí y es la voz lírica quien avisa de su sobrevivencia. Es decir, es en la intimidad de la voz poética donde la conjunción entre el mundo metafísico y el mundo natural/animal se fusionan, se encuentran, como una forma de autodefinición del ser poético. Así, este poema es una brillante muestra del aporte de la mujer maya a la literatura, no sólo de su propia comunidad, sino del corpus literario universal. Valiéndose de la disociación iglesia-Dios, no sólo poetiza esta situación sino que, por una parte, actualiza la milenaria sabiduría maya en cuanto a las relaciones de los dioses con la naturaleza y, por otra, establece una crítica a la realidad religiosa de su mundo mediante estructuras gramaticales que hablan de un "allí" donde la voz poética no se ubica. Así, esta poeta recupera un pasado ancestral a la vez que discute con su presente. 
En otro de sus poemas, Briceida Cuevas retoma una posición lírica muy similar a la anterior. En "Xnok'ol" ("Gusano") (Cuevas, 1998: 4), ${ }^{4}$ un poema con claras influencias simbolistas del tipo de "La lluvia" de Rimbaud o de los poemas epigráficos de las diferentes vanguardias, se observa cómo el texto simula el movimiento del gusano:

\author{
Gusano \\ que esbozas cerritos \\ Andas, \\ mides \\ Tus pies no se cansan \\ ¿qué mides?
}

El poema presenta la unión entre la imagen poetizada y el mundo que refiere. Pero si se toma en cuenta su forma (estructuras silábicas irregulares: 3-7-2-2-7-3), vemos en este elemento natural un valor superior a su simple existencia: es el encargado de medir la vida, la muerte, la alegría o la tristeza. Este reconocimiento hace que la voz poética hable al gusano, lo interpele, y, en esta interrelación, haga que surja una transformación que vincula al agente poético con el elemento poetizado (gusano):

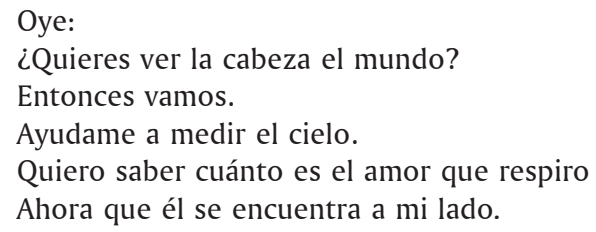

Como se puede ver, el valor del sema "gusano" no sólo muestra un tipo de conocimiento, sino también la capacidad de aceptar la transformación fruto de la inquietud del hombre. Así, se unen el mundo natural y la voz poética en el territorio del poema con el fin de "[...] medir el cielo". De tal forma, el poema finaliza con la unión, a través de la palabra poética, del hombre y del mundo natural. El amor lleva, por tanto, a un encuentro entre el mundo natural y el mundo individual que, mutuamente relacionados, pueden transformarse. Así, la poeta se erige, no sólo como la visualizadora de los valores del mundo naturalanimal, sino que además es un agente activo que, vinculado con aquel gusano, genera una transformación mutua simbolizada en el poema, mediante el rescate del valor "mediación": el "gusano" se transforma de un elemento terrestre a uno aéreo, y la voz poética, de un visualizador a un agente activo que busca conocimientos. Por otra parte, en el texto "Minanech ti k'iuik" ("La plaza sin ti”)

\footnotetext{
${ }^{4}$ Todas las referencias fueron tomadas de esta edición.
} 
(Cuevas, 1998: 4), ${ }^{5}$ Briceida nos presenta un poema amoroso en el que la voz poética habla a un "tú" ausente:

Te fuiste como se consume un cigarrillo

El humo casi te alcanza

El camino te engulle.

La lejanía te esconde.

La presencia del otro se pierde lentamente dejando una marca en el aire. Ahora, el fuego se presenta como el consumidor de la presencia del otro para, de allí, saltar a un nuevo verso que funde estos dos elementos (desaparición del "tú"-fuego): "El humo casi te alcanza". De tal forma, el símil no sólo es un recurso poético, sino que es parte integrante de la forma versificada, pues le sirve a la voz poética para establecer una comparación entre el sentimiento y el abandono. Lentamente, con un fuego tenue pero constante, el "tú" amado se aleja y la voz poética permanece en un "aquí" que visualiza cómo la lejanía se apodera del ser amado: "El camino te engulle / la lejanía te esconde". Con el ser amado cada vez más lejos, la voz poética cambia de plano y dirige su mirada en dirección a la plaza:

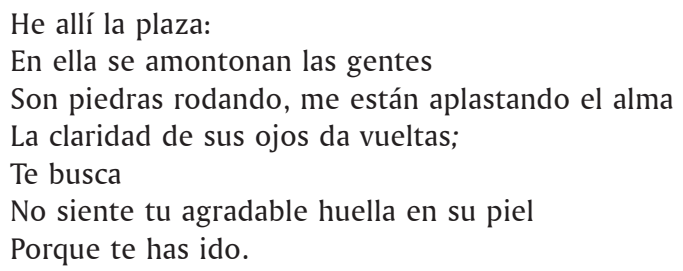

Cuando el amado se aleja se va en dirección contraria al pueblo. Esto resulta muy llamativo, pues desde los tiempos de la Conquista y la Colonia española, y luego durante guerra con la federación, la llamada Guerra de Castas (1847-1901), los mayas tuvieron un constante rechazo a concentrarse en los pueblos, pues representaba el pago de tributos e impuestos, la obligación de oficios religiosos, etc. Ahora bien, lo anterior llama la atención porque una vez que la voz poética gira en dirección al centro del pueblo (la plaza) deja de ver al "ser amado" y un profundo desasosiego se apodera de ella. Así, este cambio poético no sólo es espacial, sino que también le sirve para volver a hablar de la soledad que siente en medio de su mundo. Dice la voz poética en este momento sobre la plaza: "en ella se amontonan las gentes; / son piedras rodando". Ahora, estos "otros" (las gentes) aparecen, frente al "yo" de la voz poética, como seres inanimados ("piedras") que se encuentran en movimiento y que, finalmente, tienden a aplastar al "yo" poético: "me están aplastando el alma". A continuación vuelve sobre la

\footnotetext{
${ }^{5}$ Todas las referencias fueron tomadas de esta edición.
} 
plaza, pero ahora algo se produce dentro del poema: "La claridad de sus ojos da vueltas; te busca”. Así, una vez más, un espacio geográfico (abierto como es la plaza) se presenta con un rasgo humano: siente. El mundo espacial, al igual que el "yo" poético, siente el abandono del "tú" amado. De nuevo, al igual que en los poemas antes comentados, la poeta logra la conjunción entre el mundo del "yo" poético y el mundo exterior (en este caso la "plaza") encontrando en ellos un distanciamiento frente al mundo de los hombres.

Valores innegables son los que alcanza la poesía de Briceida Cuevas Cob, poeta que no sólo entra a un sistema unido a una tradición occidental (que nace del romanticismo y llega a las vanguardias literarias), por medio de temáticas recurrentes que desarrollan la escisión con el mundo natural y el mundo interior del "yo", sino que, además, logra la coexistencia entre las formas y las temáticas poéticas para establecer (y éste es, tal vez, su aspecto primordial), usando figuras ágiles, la concatenación entre los diferentes elementos del cosmos en búsqueda de una armonía que retraiga una reconciliación entre el mundo mágico, el mundo natural y el mundo social e individual, mediante la actualización de principios culturales que han sobrevivido en algunas poblaciones mayas.

\section{Silvia Canché Cob: la alegría de vivir}

Nacida en Tepekán, Calkiní (Campeche), es autora de diversos poemas llenos de lirismo donde toda la naturaleza, los astros y el ser amado son dispuestos para expresar la alegría interior de la experiencia de vivir. Por ejemplo, su poema "Maasoob" ("Los grillos") (Canché, 1998: 5) ${ }^{6}$ inicia con un verso que, al definir, caracteriza: "La noche es bella". En esta afirmación la poeta establece una lectura del mundo: no escogiendo el valor "oscuridad" del sema "noche" (que, dentro de la tradición occidental, pudiera asociarse con el espacio para los amantes, para la calma o el miedo). En contraposición, más que el silencio, ella encuentra en la noche el sonido: "Los grillos gustosamente cantan":

La noche es bella.

Los grillos gustosamente cantan

Cantan con gozo para mí.

Cuando levanto los ojos,

Veo cómo placenteramente danzan en el pequeño rincón de mi casa.

Cuando la voz poética afirma "Cantan con gozo para mí", pareciera que la noche se presenta como un espectáculo dirigido al "yo" poético. Aclaramos que usamos el concepto espectáculo, en una acepción simple, como el montaje o presentación que un "otro" hace para ser presenciado por una serie de "yos". En

\footnotetext{
${ }^{6}$ Todas las referencias fueron tomadas de esta edición.
} 
este caso, nada más inexacto pues: "Cuando levanto los ojos, / veo como placenteramente danzan en el pequeño rincón de mi casa”.

Los versos de esta poeta son de gran valía y merecen un comentario detenido. Inicialmente se debe decir que la noche percibida por la voz poética como bella no es la del cielo (arriba), ni la de la lejana oscuridad (frente), sino un retrotraerse al interior (abajo): por ello, el hablante lírico levanta sus ojos. Así, esta noche es de recogimiento, lo cual, en el poema, la hace bella. Esa intimidad permite que la vivencia de lo bello sea en el espacio privado: los grillos cantan dentro de su propia casa, cumpliendo, por tanto, dos funciones. Por un lado, la no separación en dualidad del par espectáculo-espectador, y, por otro, la convivencia íntima y directa con la naturaleza. Ahora, a pesar de que todo esto se genera dentro de la casa, no se desliga del mundo exterior sino que, muy al contrario, "los grillos bailan con la lluvia". Así, el encuentro entre la voz poética y los grillos está en directa relación con el mundo exterior mediante el elemento lluvia.

\section{La lluvia brinca con agrado en los ramajes. \\ Los grillos bailan con la lluvia. \\ Cuando la lluvia se vuelve finas hebras \\ Dejo de escuchar el gratísimo canto de los grillos.}

Como se sabe, el deseo de lluvias, la persecución del agua, dentro de la cultura maya ha sido piedra fundamental de su religiosidad y de su sobrevivencia. Por ello, el dios Chac (dios del agua) es uno de los más presentes en la siempre cálida Península de Yucatán. Esto permite reordenar, en segundo grado, el poema. La noche íntima y personal de la voz poética "vive" una gran celebración (cantos de los grillos) gracias a la aparición de la lluvia que "[...] brinca con agrado en los ramajes". El poema se cierra: "Cuando la lluvia se vuelve finas hebras, / dejo de escuchar el gratísimo canto de los grillos". De esta manera, el poema no termina con silencio que deja cansancio o sobresalto, al contrario, termina en silencio que es descanso después de la fiesta que trajo la lluvia. En esta configuración poética, la noche es bella porque, gracias a la lluvia todos los seres dirigen su atención al concierto de los grillos. En este "inocente" poema de Silvia Canché, se vuelbe a encontrar una consonancia entre los animales (grillos), la naturaleza (lluvia) y el "yo" (voz poética), donde existe una alegría que, en unión indisoluble, se apropia de la noche para redefinirla.

\section{Margarita Kú Xool: Las voces de la naturaleza}

Nacida en Santa Cruz, Calkiní (Campeche), su obra poética evidencia el encuentro de los diversos seres y elementos de la naturaleza mostrándonos el ambiente de armonía en que viven. Por ejemplo, su poema "Cahn much yétel chan pepen" ("La ranita y la mariposita") (Kú, 1998: 12) habla del encuentro entre una ranita que

\footnotetext{
7 Todas las referencias fueron tomadas de esta edición.
} 
canta y una mariposita recién salida del capullo. Así, lo que antes era el alimento de la rana (mariposita) se transforma, ahora, en emoción, por lo que: "Despertó su corazón":

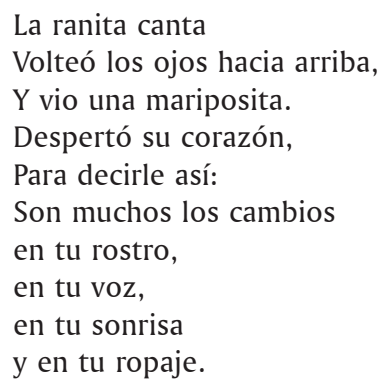

El cambio en su "rostro", su "voz", su "sonrisa", informa de la sensibilidad que la voz poética percibe entre los seres de la naturaleza. Ahora, esta transformación convierte a la ranita en el elemento que brinda la posibilidad de cuidar y enseñar la vida a la mariposa. Por ello le dice:

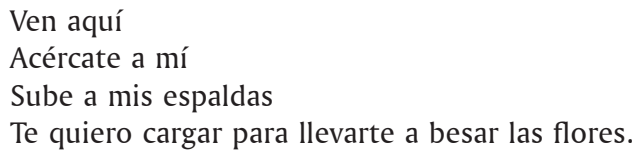

Esta mancomunidad entre los elementos de la naturaleza que no admite separación entre el hombre y la naturaleza es piedra fundamental de la literatura maya (ésta siente, al igual que aquellos). Sin embargo, Margarita Kú Xool no sólo aborda las relaciones entre animales, sino también entre otros elementos naturales. Por ejemplo, en su poema "Ak'ab yetel ik'” (“La noche y el viento") (Kú, 1998: 12) habla de la relación juguetona que la noche establece con el viento, profundamente unida, en su aparente candidez, con la realidad climática de la península. En efecto, la noche (luego de los calurosos días) es el momento en que, gracias al viento que sopla del mar, se puede lograr un descanso relajado. Por eso, en ese poema:

La noche duerme plácidamente.

Ronca de placer.

Abraza con gozo el viento por el cuello.

Lo aprieta con gusto

Así, lo que para un lector desconocedor del contexto pudiera ser un poema sin muchos valores simbólicos, refiere una situación felizmente cotidiana entre los mayas. Esto último, tal vez, es lo que define de una manera más exacta la poesía de Margarita Kú Xool: nos habla de lo cotidiano para recordarnos lo evidente; aquello que por evidente, quizá, pasa desapercibido. 


\section{Deslindes y aportaciones}

En resumen, el subgénero lírico en la literatura maya contemporánea es particularmente elegido por las escritoras mayas provenientes de la región de Calkiní (Campeche) para su trabajo literario. En los textos presentados, se establece el centro en la autoafirmación de un "yo" que, a diferencia de la lírica occidental, presenta su punto nodal en una incapacidad de encuentro con el "tú" solamente humano. Dicha situación se expresa en una búsqueda de retorno que unificaría el "yo" con la totalidad expresada en el "tú" pero a partir de la comunión o interrelación con la naturaleza. La afirmación expresada en la intimidad poética es que "yo" y "tú" sólo somos posibles en el mundo que forma parte del mundo natural. Lo anterior produce un nuevo esquema del evento lírico, según el siguiente gráfico:

$$
\text { [yo } \longrightarrow \text { (naturaleza-yo) } \longrightarrow \text { (tú) } \longrightarrow \longrightarrow \text { yo-tú } \neq \text { él }
$$

Tal percepción resulta una real modificación que, claramente, se distancia de la tradición occidental, la cual, nacida del universo ilustrado de los siglos xVII y xVIII, separó al hombre del mundo natural (para hacerlo objeto de dominio) y se preocupó, particularmente, de la no identidad entre "yo" y "tú" en la construcción del individualismo propio del mundo occidentalizado. Dicha percepción se expresa, entre otras formas, en los lenguajes por medio de los cuales va a referenciar la realidad desde el perfil occidental. En efecto, en la Europa de los siglos XVI a XVIII, las lenguas nacionales se difunden en las colonias de ultramar dando inicio a un proceso donde el hombre comienza a percibir una nueva forma de vida en la cual el antiguo lenguaje se mostraba incompleto y diferente: el objetivo era dominar a la naturaleza de la cual los "otros" eran extensión. Resulta sintomático en tal sentido que la palabra modernidad naciera en este mismo momento.

Jean-Jacques Rousseau es el primero en hablar de modernidad en su novela romántica Julie o la nueva Eloísa. En ella, la define como un "torbellino social" que se encuentra expresado, en primer lugar, por su capital, París. En efecto, el joven protagonista, Saint-Preux, va del campo a la ciudad y, en cartas que escribe a su amada, Julie, le describe su miedo y asombro ante esta nueva realidad, pues la vida metropolitana era "[...] un choque perpetuo de grupos y cábalas, un flujo y reflujo continuo de prejuicios y opiniones en conflicto" (Rousseau, 1959: 233). Esta dinámica, donde la diferencia entre lo bueno y lo malo no es evidente y la imposición de lo pasajero parece la verdad última, sobrecoge al personaje: "Se debe ajustar su espíritu a cada paso" (Rousseau, 1959: 255). Nace, de tal forma, la "embriaguez" exaltada como la forma de percepción de lo cotidiano, el "vértigo" como un ritmo respiratorio del cual no se puede escapar en este nuevo mundo urbano. Las consecuencias de esta realidad son el rompimiento con su propia forma de definirse y, por tanto, con su sentido de pertenencia: la modernidad, expresada en esta dirección, es el abandono del pasado y la separación con el mundo natural. 
Desde ese enfoque, el nuevo hombre tendrá un valor supremo: su no atadura a un pasado trascendente, en tanto que, ahora, redefinido para las nuevas nociones, podrá construir un nuevo tiempo, una nueva identidad. Deberá, en esta dirección, afianzar su esencia en una "libertad" y una "igualdad" absolutamente novedosas que, muy al contrario de cualquier visión enaltecedora del hombre, conllevan al desarraigo y al distanciamiento del "tú".

Ahora, este vuelco hacia la individualidad no conlleva una restitución del individuo. Muy al contrario, más que realizarse una transformación de su totalidad, el discurso que hace referencia a un mundo externo se amplía (alcanza un mayor corpus) pero, a su vez, hace que los lenguajes se deslinden. Aumenta, de tal forma, el lexicón para dirigirse al proceso de apropiación del mundo "externo", en tanto, propugnando una inalienable libertad, el lenguaje que crea-habla de la interioridad queda desprotegido de un parámetro que guíe su expresión. Es más, es tan avasalladora la presencia de un lenguaje que habla del mundo externo (en tanto descripción y dominación del mismo) que la interioridad del individuo comienza a perder la capacidad para referirse a "sí mismo" debido, precisamente, a la indeterminación creciente en su forma de percibirse. El fin de esta modificación será, por supuesto, la incapacidad para autoreferenciarse mientras que despliega un saber nunca antes visto que le posibilita, en última instancia, el dominio del mundo mediante el desarrollo.

Es decir, el hombre de la modernidad abandona su identidad para lograr un mundo liberado donde, diverso a lo prometido, se obtiene una emancipación que, ahora, no tiene nada que liberar: engrandecido por la libertad, su "yo" se ha quedado vacío, distante del mundo y separado del "tú". Así, en un constante sentido de abandono, la libertad del nuevo hombre creó, ante todo, un infinito sentido de pérdida.

En esta dinámica, la concepción del amor se transforma (y eso se puede ver en numerosos poetas del romanticismo) en la necesidad de encontrar lo ausente, en recuperar lo abandonado: es amor a "lo que fui". Pero, al mismo tiempo, es amor a "donde no soy": la geografía exótica y el paraíso perdido se convierten en los paradigmas culturales de un mundo que, al dirigir su ejercicio cotidiano hacia la dominación del mundo (vía la libertad), pierde la potencialidad del sueño para volcarse, furiosamente, sobre un único y soñado destino: el desarrollo. Pero, a su vez, cuando más logrado éste, más abandonado, solitario e incapacitado para soñar. Los costos de la modernidad serán altos pues, en tanto se ejerce rabiosamente esta libertad para el dominio, el hombre queda imposibilitado para vivir en el mundo.

Diferente a estos procesos evidentes en la historia de la lírica occidental, la lírica maya contemporánea, expresada en las tres poetas mencionadas en este ensayo, se dirige, en una forma novedosa de apropiación de dicha tradición, a clamar la fusión con el "tú" (totalidad), pero que no se expresa únicamente en el amado, sino en la naturaleza. Lo anterior invita e impulsa al lector de la poesía maya contemporánea a no mirar en estos textos una simple reelaboración de 
la tradición lírica occidental o una sencilla recopilación de antiguas tradiciones, sino un constructo simbólico diferente e insinuante que invita a leer/vivir el mundo desde una perspectiva cultural maya contemporánea.

\section{BIBLIOGRAFÍA}

Bajtín, Mijaíl

1997 Estética de la creación verbal. México: Siglo XXI.

Barrera Vásquez, Alfredo

1980 El libro de los cantares de Dzitbalché. Mérida, Yucatán: Ayuntamiento de Mérida.

Beristáin, Helena

1989 Análisis e interpretación del poema lírico. México: Universidad Nacional Autónoma de México.

Canché Cob, Silvia

1998 "Maasoob (Los grillos)”, Navegaciones Zur, 20: 5. Mérida, Yucatán: Centro Yucateco de Escritores A. C.

Cros, Edmund

1986 Literatura, ideología y sociedad. Madrid: Gredos.

Cuevas Cob, Briceida

1998a “Xnok'ol (Gusano)” y “Minanech ti k'iuik (La plaza sin ti)”, Navegaciones Zur, 20: 4. Mérida, Yucatán: Centro Yucateco de Escritores A. C.

1998b “U yok'ol auat pek' ti u kuxtal pek' (El quejido del perro en su existencia)", La Palabra Florida, 2 (5): 13. México: Asociación de Escritores en Lenguas Indígenas A. C.

Enciclopedia Yucatán en el tiempo

1999 Tomo VI. México: Inversiones CARES.

Foucault, Michel

1987 La arqueología del saber. México: Siglo XXI.

Glowinski, Michal

2002 "Los géneros literarios”, Teoría literaria, pp. 93-109, Marc Angenot, Jean Bessiere, Douwe Fokkema y Eva Kushner (directores). México: Siglo XXI.

Gordon, G. B. y John Alden Mason

1925-43 Examples of Maya Pottery in the Museum and Other Collections. Philadelphia: University of Pensylvania - The University Museum.

Jakobson, Roman

1973 Questions de poétique. París: Seuil. 
Kayser, Wolfgang

1961 Interpretación y análisis de la obra literaria. Madrid: Gredos.

Kú Xool, Margarita

1998 “Ak'ab yetel ik' (La noche y el viento)” y “Chan much yétel chan pepen (La ranita y la mariposita)”, Navegaciones Zur, 20: 12. Mérida, Yucatán: Centro Yucateco de Escritores A. C.

Leirana Alcocer, Silvia Cristina

2011 Catálogo de textos mayas publicados entre 1990 y 2009 (Bibliografía comentada). Mérida, Yucatán: Instituto de Cultura de Yucatán.

Ligorred Perramon, Francesc

1997 U mayathanoob ti dzib (Las voces de la escritura). Mérida, Yucatán: Universidad Autónoma de Yucatán.

Lipovertsky, Gilles

1996 El crepúsculo del deber. La ética indolora de los nuevos tiempos democráticos. Barcelona: Anagrama.

Lukács, Georg

1985 El alma y las formas. México: Grijalbo.

Ortega Arango, Oscar

2010 Tradición y renovación: Literatura maya yucateca contemporánea. Austria/México: Academic Publishers.

Rousseau, Jean-Jacques

1959 Julie o la nueva Eloísa, en Obras Completas II. Paris: Gallimard.

Segre, Cesare

1985 Principios de análisis del texto literario. Barcelona: Grijalbo.

Sharer, Robert J.

1998 La civilización maya. México: Fondo de Cultura Económica.

Thompson, J. Eric S.

1975 Historia y religión de los mayas. México: Siglo XXI.

Yershova, Galina

1983 “Lírica maya de la antiguiedad”, América Latina, 7: 39-62. Moscú: Progreso. 
